\title{
High-gain $\mathrm{Al}_{2} \mathrm{O}_{3}: \mathrm{Nd}^{3+}$ channel waveguide amplifiers at $880 \mathrm{~nm}$, $1060 \mathrm{~nm}$, and $1330 \mathrm{~nm}$
}

\author{
J. Yang • K. van Dalfsen · K. Wörhoff • F. Ay • \\ M. Pollnau
}

Received: 2 February 2010 / Published online: 14 July 2010

(c) The Author(s) 2010. This article is published with open access at Springerlink.com

\begin{abstract}
Neodymium-doped aluminum oxide films with a range of $\mathrm{Nd}^{3+}$ concentrations are deposited on silicon wafers by reactive co-sputtering, and single-mode channel waveguides with various lengths are fabricated by reactive ion etching. Photoluminescence at 880, 1060, and $1330 \mathrm{~nm}$ from the $\mathrm{Nd}^{3+}$ ions with a lifetime of $325 \mu \mathrm{s}$ is observed. Internal net gain at $845-945 \mathrm{~nm}, 1064$, and $1330 \mathrm{~nm}$ is experimentally and theoretically investigated under continuous-wave excitation at $802 \mathrm{~nm}$. Net optical gain of $6.3 \mathrm{~dB} / \mathrm{cm}$ at $1064 \mathrm{~nm}$ and $1.93 \mathrm{~dB} / \mathrm{cm}$ at $1330 \mathrm{~nm}$ is obtained in a 1.4-cm-long waveguide with a $\mathrm{Nd}^{3+}$ concentration of $1.68 \times 10^{20} \mathrm{~cm}^{-3}$ when launching $45 \mathrm{~mW}$ of pump power. In longer waveguides a maximum gain of $14.4 \mathrm{~dB}$ and $5.1 \mathrm{~dB}$ is obtained at these wavelengths, respectively. Net optical gain is also observed in the range $865-930 \mathrm{~nm}$ and a peak gain of $1.57 \mathrm{~dB} / \mathrm{cm}$ in a short and $3.0 \mathrm{~dB}$ in a 4.1-cm-long waveguide is obtained at $880 \mathrm{~nm}$ with a $\mathrm{Nd}^{3+}$ concentration of $0.65 \times$ $10^{20} \mathrm{~cm}^{-3}$. By use of a rate-equation model, the gain on these three transitions is calculated, and the macroscopic parameter of energy-transfer upconversion as a function of $\mathrm{Nd}^{3+}$ concentration is derived. The high internal net gain indicates that $\mathrm{Al}_{2} \mathrm{O}_{3}: \mathrm{Nd}^{3+}$ channel waveguide amplifiers are suitable for providing gain in many integrated optical devices.
\end{abstract}

J. Yang $(\varangle) \cdot$ K. van Dalfsen · K. Wörhoff · F. Ay · M. Pollnau Integrated Optical Micro Systems Group, MESA+ Institute for Nanotechnology, University of Twente, P.O. Box 217, 7500 AE Enschede, The Netherlands

e-mail: j.yang@ewi.utwente.nl

Fax: +31-53-489-3343

\section{Introduction}

Over the last two decades there has been significant interest in rare-earth-ion-doped planar waveguide amplifiers [1-9] for integrated optical applications. Such low-cost, compact components can be very useful for amplifying optical signals at a high data rate of $170 \mathrm{Gbit} / \mathrm{s}$ [8] and compensating optical losses owing to waveguide materials, signal routing, and input/output coupling within an integrated optical circuit.

Neodymium-doped waveguide amplifiers $[1-3,5,6]$ and lasers [10-12] are of interest for applications at the ion's specific emission wavelengths. The $\mathrm{Nd}^{3+} 1060-\mathrm{nm}$ gain transition $\left({ }^{4} \mathrm{~F}_{3 / 2} \rightarrow{ }^{4} \mathrm{I}_{11 / 2}\right)$ has been widely studied. It has a fourlevel-energy structure and a large emission cross-section, which provides significant gain at low excitation power for optical amplification. Emission on the ${ }^{4} \mathrm{~F}_{3 / 2} \rightarrow{ }^{4} \mathrm{I}_{9 / 2}$ ground-state transition around $865-930 \mathrm{~nm}$ is of interest for signal amplification in integrated optical applications, e.g., data transmission in optical interconnects [13-16] and medical diagnostics [17, 18]. Furthermore, the excited-state transition ${ }^{4} \mathrm{~F}_{3 / 2} \rightarrow{ }^{4} \mathrm{I}_{13 / 2}$ at $1330 \mathrm{~nm}$, corresponding to the wavelength of the second standard telecommunication window, is used for high-speed amplification of optical signals at the telecommunication O-band (1260-1360 nm).

Amorphous aluminium oxide $\left(\mathrm{a}-\mathrm{Al}_{2} \mathrm{O}_{3}\right)$ has been investigated as a gain material due to its low loss, good mechanical stability and-compared to other amorphous dielectric materials-large thermal conductivity and refractive index, the latter property allowing high integration density [7]. Besides, $\mathrm{Al}_{2} \mathrm{O}_{3}$ is compatible with Si-based technology. Previously, Er-doped $\mathrm{Al}_{2} \mathrm{O}_{3}$ has been studied as a gain medium and a peak gain of $2 \mathrm{~dB} / \mathrm{cm}$ at $1533 \mathrm{~nm}$, and net gain over a wide wavelength range of $80 \mathrm{~nm}$ has been demonstrated [9].

In this work, $\mathrm{Al}_{2} \mathrm{O}_{3}$ is used as the host material for $\mathrm{Nd}^{3+}$. A maximum 14.4- $\mathrm{dB}$ and $5.1-\mathrm{dB}$ gain is demonstrated 
at $1064 \mathrm{~nm}$ and $1330 \mathrm{~nm}$, respectively, in a 4.1-cm-long $\mathrm{Al}_{2} \mathrm{O}_{3}: \mathrm{Nd}^{3+}$ channel waveguide. In addition, gain around $865-930 \mathrm{~nm}$ is observed, and a peak gain of $3.0 \mathrm{~dB}$ at $880 \mathrm{~nm}$ is achieved. Energy-transfer upconversion (ETU) of $\mathrm{Nd}^{3+}$ ions in the $\mathrm{Al}_{2} \mathrm{O}_{3}$ host is studied by measuring luminescence decay curves, as well as in gain calculations by use of a rate-equation model. The macroscopic ETU parameter as a function of $\mathrm{Nd}^{3+}$ concentration is derived.

\section{Waveguide fabrication and spectroscopic characterization}

\subsection{Waveguide fabrication}

Deposition of planar $\mathrm{Al}_{2} \mathrm{O}_{3}$ waveguides with and without rare-earth-ion dopants has been optimized by use of an AJA ATC 1500 reactive sputtering system equipped with RF sputtering guns, resulting in layers with low background loss [7]. Here, $\mathrm{Al}_{2} \mathrm{O}_{3}: \mathrm{Nd}^{3+}$ layers with a thickness of $600 \mathrm{~nm}$ were reactively co-sputtered by the same system onto 8- $\mu \mathrm{m}$ thermally oxidized Si wafers. High-purity Al and Nd metallic targets were sputtered using Ar guns, while oxygen was supplied as a gas. By varying the Nd-target power, layers have been obtained with seven different $\mathrm{Nd}^{3+}$ concentrations of $0.65,0.90,1.13,1.40,1.68,2.50$, and $2.95 \times 10^{20} \mathrm{~cm}^{-3}$. The spectroscopic characterization and gain study presented in this paper is based mainly on the four concentrations of $0.65,1.13,1.68$, and $2.95 \times 10^{20} \mathrm{~cm}^{-3}$, while investigations of the other three intermediate concentrations are discussed briefly. The refractive index of these layers was determined with the prism coupling method to be 1.669 at $633 \mathrm{~nm}$.

Straight channel waveguides were fabricated in the layers by standard lithography and reactive ion etching with a $\mathrm{BCl}_{3}-\mathrm{HBr}$ plasma [19]. One half of each layer was left unpatterned for planar waveguide experiments. The channels have a width of $2.0 \mu \mathrm{m}$ and shallow etch depth of $\sim 70 \mathrm{~nm}$, using air as the cladding. The etch depth, layer thickness, and waveguide width were selected to ensure strong confinement of the propagating optical signal within the uniformly doped $\mathrm{Al}_{2} \mathrm{O}_{3}: \mathrm{Nd}^{3+}$ layers and single-mode behavior with excellent overlap of signal and pump modes. The waveguide samples were cleaved to different lengths varying from 0.85 to $4.25 \mathrm{~cm}$.

\subsection{Loss measurements}

The broadband loss spectra of $\mathrm{Al}_{2} \mathrm{O}_{3}: \mathrm{Nd}^{3+}$ layers were measured using the prism coupling method. White light from a broadband source (FemtoPower1060, SC450, Fianium) was coupled into the film and out again after propagating an adjustable distance through the film by use of two
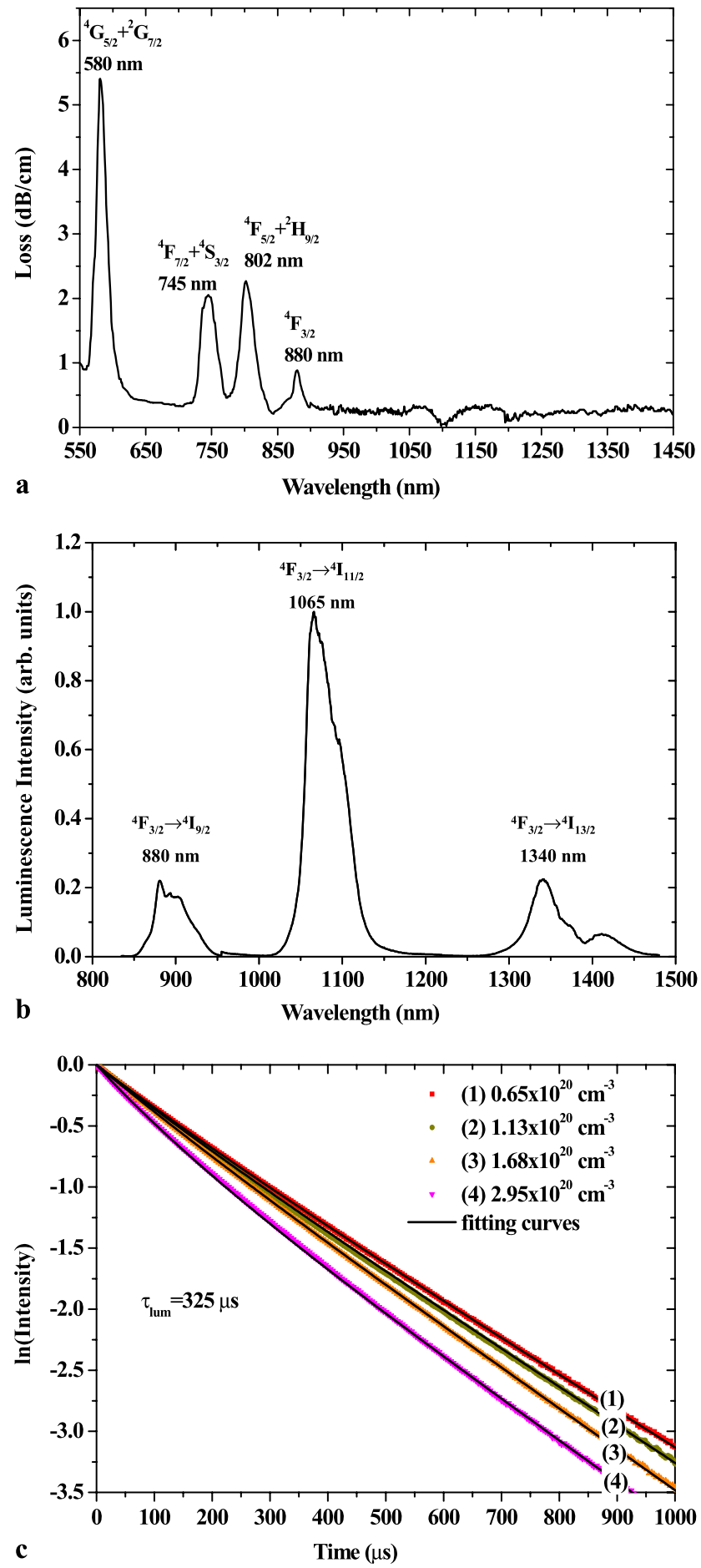

Fig. 1 (a) Broadband spectrum of propagation loss and $\mathrm{Nd}^{3+}$ absorption in an $\mathrm{Al}_{2} \mathrm{O}_{3}: \mathrm{Nd}^{3+}$ slab waveguide; (b) broadband luminescence spectrum (corrected with respect to the response curve of the detector) of an $\mathrm{Al}_{2} \mathrm{O}_{3}: \mathrm{Nd}^{3+}$ channel waveguide; (c) measured (dots) and fitted (line) luminescence decay curves at $1065 \mathrm{~nm}$ for four different $\mathrm{Nd}^{3+}$ concentrations (for clarity of the figure, the intermediate three concentrations are not shown here) in $\mathrm{Al}_{2} \mathrm{O}_{3}: \mathrm{Nd}^{3+}$ channel waveguides 
Table 1 Radiative decay rates $A_{J J^{\prime}}$, radiative lifetime $\tau_{\text {rad }}$, and branching ratios $B$ of $\mathrm{Al}_{2} \mathrm{O}_{3}: \mathrm{Nd}^{3+}$ predicted by Judd-Ofelt analysis

\begin{tabular}{llrll}
\hline Transition & Wavelength $(\mathrm{nm})$ & $A_{J J^{\prime}}\left(\mathrm{s}^{-1}\right)$ & $\tau_{\text {rad }}(\mu \mathrm{s})$ & $B$ \\
\hline${ }^{4} \mathrm{~F}_{3 / 2} \rightarrow{ }^{4} \mathrm{I}_{9 / 2}$ & $\sim 880$ & 676.1 & 474 & 0.3206 \\
${ }^{4} \mathrm{~F}_{3 / 2} \rightarrow{ }^{4} \mathrm{I}_{11 / 2}$ & $\sim 1060$ & 1164.7 & 474 & 0.5522 \\
${ }^{4} \mathrm{~F}_{3 / 2} \rightarrow{ }^{4} \mathrm{I}_{13 / 2}$ & $\sim 1330$ & 255.1 & 474 & 0.1210 \\
${ }^{4} \mathrm{~F}_{3 / 2} \rightarrow{ }^{4} \mathrm{I}_{15 / 2}$ & $\sim 1800$ & 13.1 & 474 & 0.0062 \\
\hline
\end{tabular}

prisms. The transmission spectra were collected by a largecore liquid fiber and recorded by a spectrometer (Jobin Yvon iHR550). The loss spectrum of the film (Fig. 1a) was derived by a least squares fitting of the recorded spectra. The absorption peaks at $580,745,800$, and $880 \mathrm{~nm}$ are due to absorption transitions from the ${ }^{4} \mathrm{I}_{9 / 2}$ ground state into the ${ }^{4} \mathrm{G}_{5 / 2}+{ }^{2} \mathrm{G}_{7 / 2},{ }^{4} \mathrm{~F}_{7 / 2}+{ }^{4} \mathrm{~S}_{3 / 2},{ }^{4} \mathrm{~F}_{5 / 2}+{ }^{2} \mathrm{H}_{9 / 2}$, and ${ }^{4} \mathrm{~F}_{3 / 2}$ excited states of $\mathrm{Nd}^{3+}$, respectively.

The loss in $\mathrm{Al}_{2} \mathrm{O}_{3}$ channel waveguides has been investigated in previous work [7, 19], which indicated that very low extra propagation losses were introduced in channel waveguides by patterning. In this work, the propagation losses in channel waveguides at each wavelength were determined by detecting luminescence or scattered signal light along the propagation direction by use of a CCD camera and software analysis [20,21]. Additional channel propagation losses of $0.6,0.3$, and $0.15 \mathrm{~dB} / \mathrm{cm}$ were measured in $\mathrm{Al}_{2} \mathrm{O}_{3}: \mathrm{Nd}^{3+}$ channel waveguides at 880,1064 , and $1330 \mathrm{~nm}$, respectively.

The Judd-Ofelt theory [22, 23] for the investigation of $4 f$ transitions in rare-earth-ion-doped materials was applied for studying the optical transitions of $\mathrm{Nd}^{3+}$ in $\mathrm{Al}_{2} \mathrm{O}_{3}$. The Judd-Ofelt parameters of $\mathrm{Nd}^{3+}$ were determined with the aid of the $\mathrm{Nd}^{3+}$ absorption bands measured in our waveguides, which were obtained by subtracting the background propagation loss in Fig. 1a. The obtained values are $\Omega_{2}=5.73 \times 10^{-20} \mathrm{~cm}^{2}, \Omega_{4}=2.43 \times 10^{-20} \mathrm{~cm}^{2}$, $\Omega_{6}=5.19 \times 10^{-20} \mathrm{~cm}^{2}$. With these parameters, the radiative decay rates $A_{J J^{\prime}}$, radiative lifetimes $\tau_{\text {rad }}$, and branching ratios $B$ were obtained and are presented in Table 1 .

\subsection{Luminescence measurements}

By pumping a channel waveguide at $802 \mathrm{~nm}$ with a Ti:Sapphire laser, the luminescence spectrum was measured using a spectrometer (Jobin Yvon iHR550), see Fig. 1b. Three distinct emission bands with peaks at 880,1065, and $1340 \mathrm{~nm}$ were observed, which correspond to $\mathrm{Nd}^{3+}$ transitions from the metastable ${ }^{4} F_{3 / 2}$ level to the ${ }^{4} I_{9 / 2},{ }^{4} I_{11 / 2}$, and ${ }^{4} I_{13 / 2}$ levels, respectively. Compared to the $\mathrm{Nd}^{3+}$ luminescence in crystals, which consists of a number of separate sharp peaks due to transitions between individual crystal-field levels [24], the $\mathrm{Nd}^{3+}$ luminescence bands in amorphous $\mathrm{Al}_{2} \mathrm{O}_{3}$ are broader and much less structured because of inhomogeneous line broadening, thus providing large gain bandwidths in an optical amplifier.

Luminescence decay measurements of $\mathrm{Nd}^{3+}$ in $\mathrm{Al}_{2} \mathrm{O}_{3}$ were performed using an external-cavity diode laser (Tiger, Sacher Lasertechnik) emitting at $802 \mathrm{~nm}$ as the excitation source. The laser diode was modulated by an external square-pulse generator and delivered pulses of 4-ms duration, allowing the excitation of the $\mathrm{Nd}^{3+}$ system to reach a steady state before the pump was switched off. The luminescent light was collected from the waveguide surface by a large-core liquid fiber. Figure 1c shows the luminescent decay curves measured at $1065 \mathrm{~nm}$ for four different $\mathrm{Nd}^{3+}$ concentrations. In the decay curve (1) for the lowest concentration, except for a faster decay occurring during the first $\sim 50 \mu$ s after switching off the pump excitation, which is attributed to energy-transfer upconversion (ETU) between neighboring $\mathrm{Nd}^{3+}$ ions in their ${ }^{4} \mathrm{~F}_{3 / 2}$ excited levels [25, 26], an exponential decay was observed. A luminescence lifetime of $325 \mu$ s was derived from the exponential part of the decay curve, which was independent of the excitation intensity. It is of the same order of magnitude as the radiative lifetime of $474 \mu$ s calculated by Judd-Ofelt analysis from the data of Table 1 . The decay curves (2)-(4) for higher $\mathrm{Nd}^{3+}$ concentrations exhibit an increasingly nonexponential decay owing to the effect of ETU. The study of ETU parameters of $\mathrm{Nd}^{3+}$ from the measured luminescence decay curves will be discussed in Sect. 4, together with an ETU study including the measured gain and a rate-equation model.

\section{Optical gain investigation}

\subsection{Gain measurement}

A pump-probe method was used for the small-signal-gain measurement. Pump light was provided by a Ti:Sapphire laser operating at $802 \mathrm{~nm}$. Diode lasers at 880 and $1330 \mathrm{~nm}$ and a Nd:YAG laser at $1064 \mathrm{~nm}$ were applied as the signal sources. Alternatively, for investigating the broadband gain spectrum at the ${ }^{4} \mathrm{~F}_{3 / 2} \rightarrow{ }^{4} \mathrm{I}_{9 / 2}$ ground-state transition, the Ti:Sapphire laser was tuned around 845-945 nm and used as the signal source, while an external-cavity diode laser operating at $802 \mathrm{~nm}$ was applied as pump source. After attenuation of the signal power to typically $1-10 \mu \mathrm{W}$ the smallsignal gain could be measured. A mechanical chopper was inserted into the signal beam path and connected to a lockin amplifier. Pump light and modulated signal light were combined by a dichroic mirror and coupled into and out of the waveguide via microscope objectives. The unabsorbed pump light coupled out of the waveguide was blocked by a high-pass filter (RG830 or RG850), while the transmitted signal light was measured by a germanium photodiode and 
amplified with the lock-in technique. The optical gain was determined by measuring the ratio of the transmitted signal intensities $I_{p}$ and $I_{u}$ in the pumped and unpumped case, respectively. By subtracting the waveguide background propagation and absorption losses $\alpha(\lambda)(\mathrm{dB} / \mathrm{cm})$ at the signal wavelength, the internal net gain was obtained by calculating the small-signal-gain coefficient in $\mathrm{dB} / \mathrm{cm}$ from the equation

$\gamma_{\text {meas }}(\lambda)=10 \cdot \log _{10}\left(I_{p}(\lambda) / I_{u}(\lambda)\right) / l-\alpha(\lambda)$,

where $l$ is the length of the waveguide channel. This approach eliminates coupling losses that occur in the measurement from the evaluation and provides the gain experienced by the launched signal power along the waveguide.

\subsection{Gain at $880 \mathrm{~nm}, 1064 \mathrm{~nm}$ and $1330 \mathrm{~nm}$}

For a four-level gain transition, the gain peak is expected at the peak luminescence wavelength of the transition. The same accounts for a three-level transition at high population inversion, as is typically the case under the chosen pump conditions for the waveguide geometries investigated here. Therefore, the internal net gain in our channel waveguides was measured at $880 \mathrm{~nm}$ (Fig. 2a) and $1064 \mathrm{~nm}$ (Fig. 2b), corresponding to the luminescence peaks of the ${ }^{4} \mathrm{~F}_{3 / 2} \rightarrow$ ${ }^{4} \mathrm{I}_{9 / 2}$ and ${ }^{4} \mathrm{~F}_{3 / 2} \rightarrow{ }^{4} \mathrm{I}_{11 / 2}$ transitions, respectively. For the transition ${ }^{4} \mathrm{~F}_{3 / 2} \rightarrow{ }^{4} \mathrm{I}_{13 / 2}$, due to the availability of signal source, the gain was measured at $1330 \mathrm{~nm}$ (Fig. 2c), at which the emission cross section has a value equaling $75 \%$ of its peak value at $1340 \mathrm{~nm}$. For each $\mathrm{Nd}^{3+}$ concentration, internal net gain at three to four different waveguide lengths was investigated to simultaneously maximize pumplight absorption and minimize excess propagation losses as well as, at the three-level transition, reabsorption at the signal wavelength.

The results of Fig. 2, which were measured with a launched pump power of $45 \mathrm{~mW}$, show a maximum gain of $14.4 \mathrm{~dB}$ at $1064 \mathrm{~nm}$ and $5.1 \mathrm{~dB}$ at $1330 \mathrm{~nm}$, for a $\mathrm{Nd}^{3+}$ concentration of $1.13 \times 10^{20} \mathrm{~cm}^{-3}$ and a sample length of $4.1 \mathrm{~cm}$. At $880 \mathrm{~nm}$ a peak gain of $3.0 \mathrm{~dB}$ was obtained in $3.0-$ and $4.1-\mathrm{cm}$-long waveguides with $\mathrm{Nd}^{3+}$ concentrations of $1.13 \times 10^{20} \mathrm{~cm}^{-3}$ and $0.65 \times 10^{20} \mathrm{~cm}^{-3}$, respectively.

Figure 3a displays the internal net gain per unit length measured for seven different $\mathrm{Nd}^{3+}$ concentrations at a short channel length $(0.85-1.00 \mathrm{~cm}$ for gain at $880 \mathrm{~nm}$ and 1.30 $1.65 \mathrm{~cm}$ for gain at 1064 and $1330 \mathrm{~nm}$ ). At such short lengths the pump power was not completely absorbed, i.e., it became possible to optimize the $\mathrm{Nd}^{3+}$ concentration at the three wavelengths. A maximum gain per unit length of $6.3 \mathrm{~dB} / \mathrm{cm}$ and $1.93 \mathrm{~dB} / \mathrm{cm}$ at $1064 \mathrm{~nm}$ and $1330 \mathrm{~nm}$, respectively, was observed in samples with a concentration of $1.68 \times 10^{20} \mathrm{~cm}^{-3}$, while a maximum $1.57 \mathrm{~dB} / \mathrm{cm}$ gain was

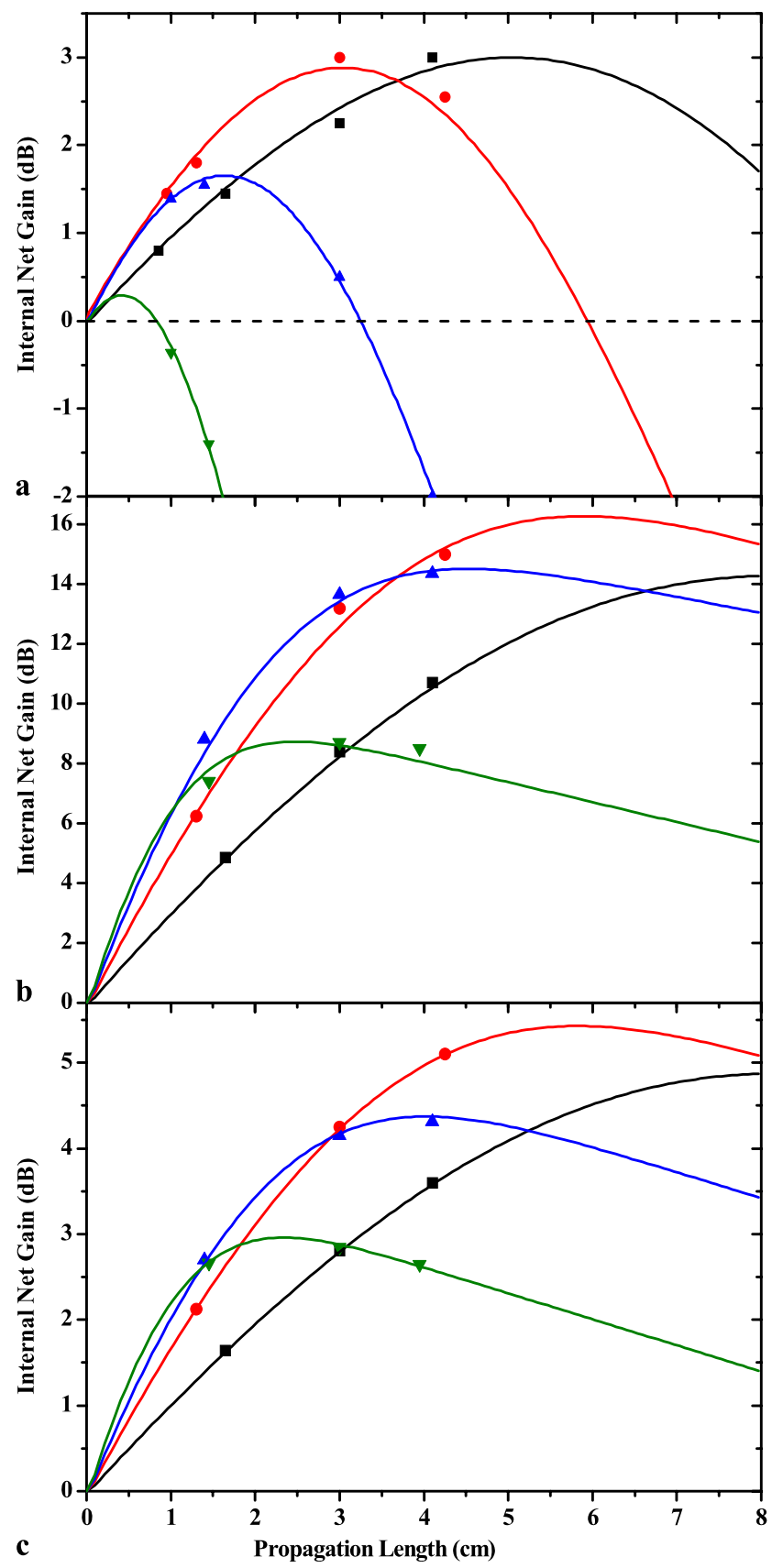

Fig. 2 Measured (dots) and calculated (lines) internal net gain at (a) $880 \mathrm{~nm}$, (b) $1064 \mathrm{~nm}$, and (c) $1330 \mathrm{~nm}$ versus propagation length for a launched pump power of $45 \mathrm{~mW}$ with different $\mathrm{Nd}^{3+}$ concentrations: $0.65 \times 10^{20} \mathrm{~cm}^{-3}(\mathbf{\square}-), 1.13 \times 10^{20} \mathrm{~cm}^{-3}(\bullet-)$, $1.68 \times 10^{20} \mathrm{~cm}^{-3}(\mathbf{\Delta}-), 2.95 \times 10^{20} \mathrm{~cm}^{-3}(\boldsymbol{\nabla}-)$

measured at $880 \mathrm{~nm}$ in a sample with $1.40 \times 10^{20} \mathrm{~cm}^{-3}$ concentration. Figure $3 b$ shows the gain in $d B / c m$ versus launched pump power in these three samples with optimum $\mathrm{Nd}^{3+}$ concentration and channel length. The gain saturation at higher pump power is mainly due to the ETU processes from ${ }^{4} \mathrm{~F}_{3 / 2}[25,26]$.

As not all the $\mathrm{Nd}^{3+}$ ions are excited in long samples due to the limitation of launched pump power and concentration- 

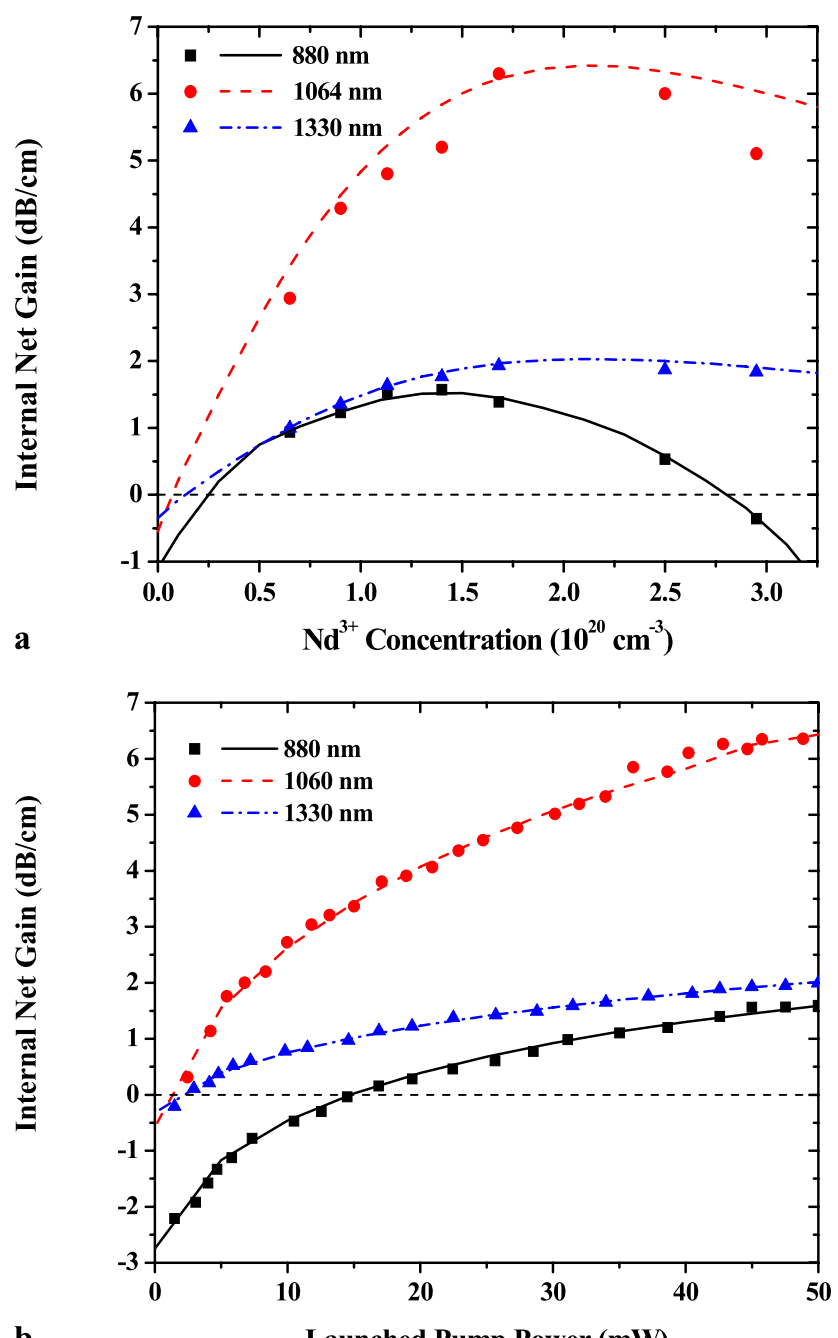

b

Launched Pump Power (mW)

Fig. 3 Measured (dots) and calculated (line) internal net gain per unit length at 880,1064, and $1330 \mathrm{~nm}$ versus (a) $\mathrm{Nd}^{3+}$ concentration for a launched pump power of $45 \mathrm{~mW}$ and (b) launched pump power for the samples with maximum gain per unit length in (a)

dependent $\mathrm{Nd}^{3+}$ absorption, the gain per unit length decreases for long propagation length. In the heavily $\mathrm{Nd}^{3+}$ doped $\left(2.95 \times 10^{20} \mathrm{~cm}^{-3}\right)$ samples, the $45-\mathrm{mW}$ launched pump power was absorbed completely within the first $2 \mathrm{~cm}$ of the channel. Consequently, there was no contribution to gain but only added propagation and potentially absorption loss at longer lengths. Since reabsorption of signal light is negligible at $1064 \mathrm{~nm}$ and $1330 \mathrm{~nm}$, higher total gain can be achieved at these two transitions in longer samples with sufficient launched pump power. Therefore, the $\mathrm{Nd}^{3+}$ concentration of $1.68 \times 10^{20} \mathrm{~cm}^{-3}$, which provides maximum gain per unit length at 1064 and $1330 \mathrm{~nm}$, is the optimal $\mathrm{Nd}^{3+}$ concentration for gain at these two wavelengths in our waveguides. At $880 \mathrm{~nm}$, although gain of $1.57 \mathrm{~dB}$ is reached in a $1.0-\mathrm{cm}$-long sample, the total gain drops significantly when increasing the channel length owing to strong reabsorption of signal light by $\mathrm{Nd}^{3+}$ ions in their ground state.
The reabsorption of $\mathrm{Nd}^{3+}$ must be taken into account when studying the gain at the $\mathrm{Nd}^{3+}$ ground-state transition.

\subsection{Gain spectrum at $845-945 \mathrm{~nm}$}

Since the three-level transition ${ }^{4} \mathrm{~F}_{3 / 2} \rightarrow{ }^{4} \mathrm{I}_{9 / 2}$ exhibits wavelength-dependent reabsorption losses when the inversion is incomplete, the gain spectrum over the whole luminescence bandwidth was investigated. The gain spectrum can be calculated from the absorption and emission cross sections of $\mathrm{Nd}^{3+}$ in $\mathrm{Al}_{2} \mathrm{O}_{3}$ using the equation

$\sigma_{\text {gain }}^{s}(\lambda)=\beta \cdot \sigma_{\text {em }}^{s}(\lambda)-(1-\beta) \cdot \sigma_{\text {abs }}^{s}(\lambda)$,

where $\sigma_{\text {gain }}^{s}(\lambda), \sigma_{\text {em }}^{s}(\lambda)$, and $\sigma_{\text {abs }}^{s}(\lambda)$ are the wavelengthdependent gain, emission, and absorption cross sections, respectively, at the signal wavelength, and $\beta$ is the fraction of excited $\mathrm{Nd}^{3+}$ ions.

The $\mathrm{Nd}^{3+}$ absorption cross section $\sigma_{\text {abs }}^{s}(\lambda)$ in $\mathrm{cm}^{2}$ was derived from the equation

$\sigma_{\mathrm{abs}}^{s}(\lambda)=\alpha_{\mathrm{Nd}}(\lambda) /\left(10 \cdot \log (e) \cdot N_{0} \cdot \Gamma\right)$,

where $N_{0}$ is the $\mathrm{Nd}^{3+}$ concentration in $\mathrm{cm}^{-3}, \alpha_{\mathrm{Nd}}(\lambda)$ is the absorption coefficient as obtained from Fig. 1a by subtracting the background loss, and $\Gamma$ is the confinement factor in the $\mathrm{Al}_{2} \mathrm{O}_{3}: \mathrm{Nd}^{3+}$ layer. The emission cross section $\sigma_{\mathrm{em}}^{S}(\lambda)$ was determined with the Füchtbauer-Ladenburg equation [27]

$\sigma_{\mathrm{em}}^{s}(\lambda)=\frac{\lambda^{4} B}{8 \pi c n^{2} \tau_{\mathrm{rad}}} \frac{I(\lambda)}{\int I(\lambda) d \lambda}$,

where $c$ is the speed of light in vacuum, $n$ is the refractive index of the medium, and $I(\lambda)$ is the intensity of measured luminescent light. The branching ratio $B$ and radiative lifetime $\tau_{\text {rad }}$ were taken from Table 1 . Both spectra are displayed in Fig. 4a. As shown in the figure, the spectra can be converted to each other by use of the McCumber theory [28],

$\sigma_{\mathrm{em}}(\lambda)=\sigma_{\mathrm{abs}}(\lambda) \cdot \frac{Z_{0}}{Z_{1}} \cdot \exp \left(\frac{E_{0}-E(\lambda)}{k T}\right)$,

where $Z_{0} / Z_{1}$ is the energy partition function based on the Stark splitting and thermal distribution of the population of the ground and excited states, $E_{0}$ is the zero-line energy, $E(\lambda)$ is the transition energy for the wavelength $\lambda, k$ is Boltzmann's constant, and $T$ is the temperature. Equal peak heights and good agreement of the spectral shapes are obtained for a partition function of $Z_{0} / Z_{1}=2.3$. The peak absorption and emission cross sections in $\mathrm{Al}_{2} \mathrm{O}_{3}: \mathrm{Nd}^{3+}$ at $880 \mathrm{~nm}$ are $0.35 \times 10^{-20} \mathrm{~cm}^{2}$ and $0.82 \times 10^{-20} \mathrm{~cm}^{2}$, respectively.

In order to compare the calculated and measured internal net gain spectra, the internal net gain coefficient in $\mathrm{dB} / \mathrm{cm}$ 


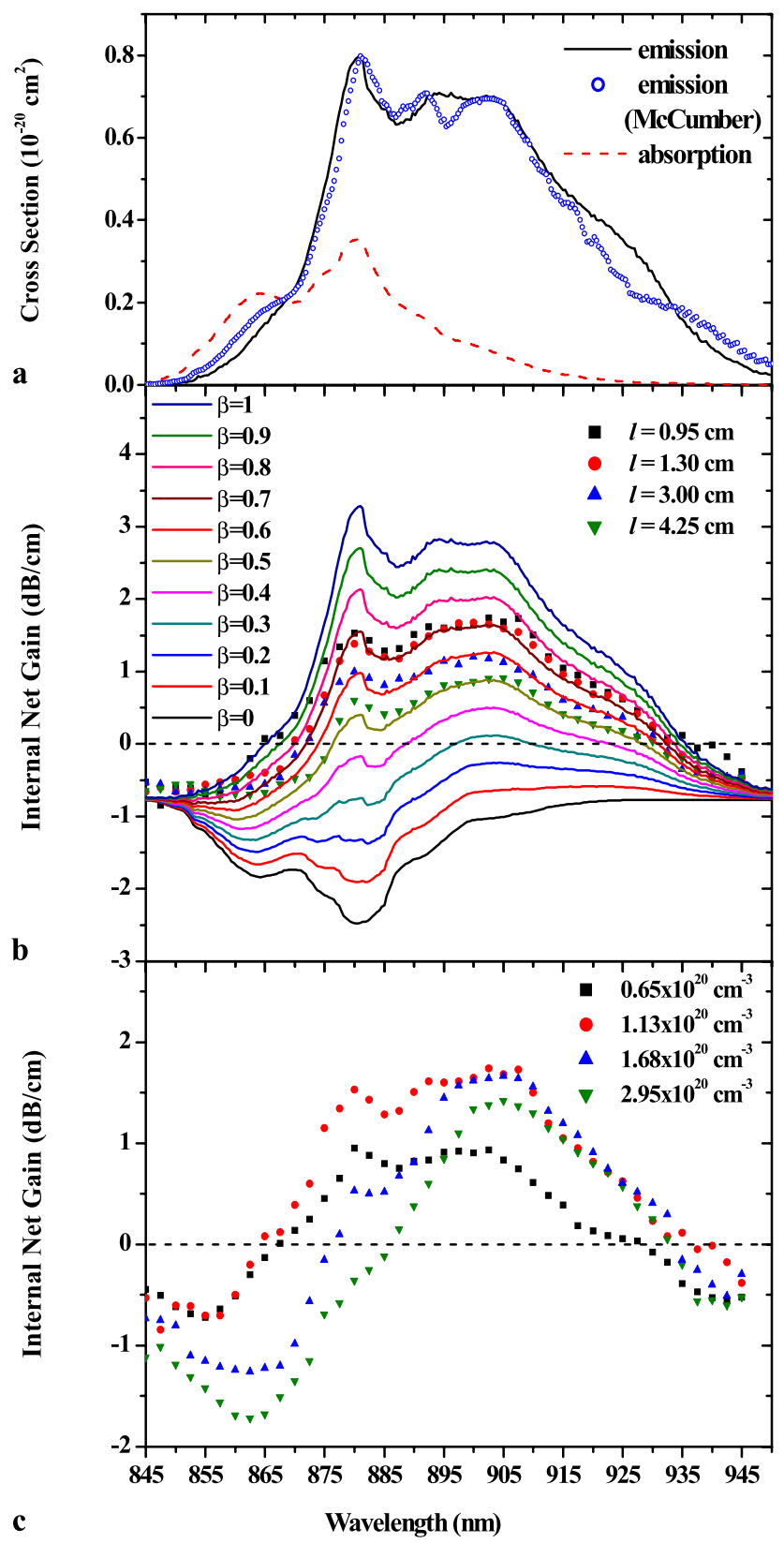

Fig. 4 Spectroscopic measurement at $845-950 \mathrm{~nm}$ of the ${ }^{4} \mathrm{~F}_{3 / 2} \leftrightarrow{ }^{4} I_{9 / 2}$ ground-state transition in $\mathrm{Al}_{2} \mathrm{O}_{3}: \mathrm{Nd}^{3+}$ channel waveguides. (a) Emission (solid line) and absorption (dash line) cross sections and emission cross section (dotted line) derived from the absorption cross section by McCumber theory; internal net gain at a launched pump power of $45 \mathrm{~mW}$ (b) for different propagation lengths with $\mathrm{Nd}^{3+}$ concentration of $1.13 \times 10^{20} \mathrm{~cm}^{-3}$ and (c) for different $\mathrm{Nd}^{3+}$ concentrations with propagation lengths of $0.85-1.00 \mathrm{~cm}$

was calculated from the gain cross section using the equation

$\gamma_{\text {calc }}(\lambda)=\sigma_{\text {gain }}^{s} \cdot 10 \cdot \log (e) \cdot N_{0}$

Figure $4 \mathrm{~b}$ compares the gain spectrum at $845-945 \mathrm{~nm}$ calculated for different excitation fractions to those measured in waveguides with four different channel length, for a $\mathrm{Nd}^{3+}$ concentration of $1.03 \times 10^{20} \mathrm{~cm}^{-3}$ and a launched pump power of $45 \mathrm{~mW}$. The measured and calculated internal net gain spectra show good agreement at excitation fractions $\beta$ of $0.72,0.69,0.62$, and 0.54 for sample lengths of $0.95,1.30$, 3.00 , and $4.25 \mathrm{~cm}$, respectively. As expected, the results of Fig. $4 \mathrm{~b}$ show that the gain peak on the ground-state transition is not always at the luminescence peak but strongly depends on population inversion. For high excitation fractions, the gain peak is close to the luminescence peak at $880 \mathrm{~nm}$, while for low excitation fractions, the gain peak moves to longer wavelengths.

The gain spectrum was also measured with channel length of $0.85-1.00 \mathrm{~cm}$ for various $\mathrm{Nd}^{3+}$ concentrations at a launched pump power of $45 \mathrm{~mW}$ (Fig. 4c). From the measured results in Figs. $4 \mathrm{~b}$ and 4c, the broadest gain bandwidth observed in our waveguides was $865-930 \mathrm{~nm}$.

\section{Simulations and ETU parameter}

With the aid of a rate-equation model, the optical gain in our waveguides at 880,1064, and $1330 \mathrm{~nm}$ was simulated, and the ETU parameter was determined as a function of $\mathrm{Nd}^{3+}$ concentration by fitting the simulated to the experimental results. In addition, the ETU parameter was determined from the measured luminescence decay curves.

\subsection{Rate-equation model and gain simulation}

The $\mathrm{Nd}^{3+}$ transition ${ }^{4} \mathrm{~F}_{3 / 2} \rightarrow{ }^{4} \mathrm{I}_{9 / 2}$ around $880 \mathrm{~nm}$ is a three-level transition. $\mathrm{Nd}^{3+}$ ions are excited at $802 \mathrm{~nm}$ from the ground state ${ }^{4} I_{9 / 2}$ to the pump level ${ }^{4} \mathrm{~F}_{5 / 2}$ followed by a fast decay to the metastable excited state ${ }^{4} F_{3 / 2}$. Since all other excited states in $\mathrm{Nd}^{3+}$ exhibit fast multiphonon relaxation and have very short lifetimes, the rate equations describing the population mechanisms of this system can be simplified as follows [25, 26]:

$$
\begin{aligned}
& d N_{4} / d t=R_{05}-R_{40}+R_{04}-\tau_{4}^{-1} N_{4}-W_{\mathrm{ETU}} N_{4}^{2}, \\
& N_{0}=N_{d}-N_{4},
\end{aligned}
$$

where $N_{4}$ and $\tau_{4}$ are the population density and lifetime of the ${ }^{4} \mathrm{~F}_{3 / 2}$ level, respectively, $N_{0}$ is the ground-state population density, and $N_{d}$ is the dopant concentration. To study the effect of ETU, three ETU processes originating in the metastable ${ }^{4} \mathrm{~F}_{3 / 2}$ level of the $\mathrm{Nd}^{3+}$ system were taken into account and expressed by a single macroscopic parameter $W_{\text {ETU }}$ in the simulation, as these processes lead to similar results concerning the population dynamics in the $\mathrm{Nd}^{3+}$ system [25]. The rates of pump absorption $R_{05}$, signal reabsorption $R_{04}$ and stimulated emission $R_{40}$ can be expressed 
as follows:

$R_{05} \approx \sigma_{\mathrm{abs}}^{p} \frac{\lambda_{p}}{h c} I_{p} N_{0}$,

$R_{04} \approx \sigma_{\mathrm{abs}}^{s} \frac{\lambda_{s}}{h c} I_{s} N_{0}$

$R_{40} \approx \sigma_{\mathrm{em}}^{s} \frac{\lambda_{s}}{h c} I_{s} N_{4}$

where $\sigma_{\text {abs }}^{p}, \sigma_{\text {abs }}^{s}$, and $\sigma_{\text {em }}^{s}$ are the pump-absorption, signalabsorption, and stimulated-emission cross sections, $\lambda_{p}$ and $\lambda_{s}$ are the wavelengths and $I_{p}$ and $I_{s}$ the intensities of pump and signal light, respectively, launched into the waveguide in propagation direction $z$, and $h$ is Planck's constant. At steady state, we can solve the above equations analytically.

Since the terminating states ${ }^{4} \mathrm{I}_{11 / 2}$ and ${ }^{4} \mathrm{I}_{13 / 2}$ of the transitions at 1064 and $1330 \mathrm{~nm}$, respectively, exhibit a very short lifetime on the order of a few ns, these transitions constitute four-level systems. The reabsorption at the signal wavelength can be neglected, and the rate equations can be simplified further as follows:

$$
\begin{aligned}
& d N_{4} / d t=R_{05}-R_{4 i}-\tau_{4}^{-1} N_{4}-W_{\mathrm{ETU}} N_{4}^{2}, \\
& \quad i=1,2 \\
& N_{0}=N_{d}-N_{4}, \\
& R_{4 i} \approx \sigma_{\mathrm{em}}^{s} \frac{\lambda_{s}}{h c} I_{s} N_{4}, \quad i=1,2 .
\end{aligned}
$$

In addition to discretization in the propagation direction $z$, a radial discretization $[23,24]$ was included in the simulation. The optical mode profiles and confinement of optical power within the polymer channel waveguides were determined by the finite difference method and using geometry and refractive indices of the channel waveguides (Table 2), with the aid of the FieldDesigner software package (PhoeniX [29]). The percentage of pump and signal power outside the active region, which does not contribute to the population dynamics, was not taken into account in the simulation. The optical mode profiles were then approximated by Gaussian profiles. The amount of pump or signal power $P_{P / S}(r, z)$ passing through a circle of radius $r$ at a propagation distance $z$ is described by the equation

$P_{P / S}(r, z)=P_{P / S, \text { total }}(z)\left[1-\exp \left(\frac{-2 r^{2}}{w_{P / S}^{2}}\right)\right]$,

where $P_{P / S \text {,total }}(z)$ is the total power propagating at a distance $z$, and $w_{P / S}$ is the Gaussian beam waist of pump and signal mode, respectively, which is defined as the radial distance at which the optical intensity drops to $1 / e^{2}$ of its peak value. The total remaining power of pump and signal beams were each redistributed in a Gaussian profile before entering the next longitudinal propagation step.
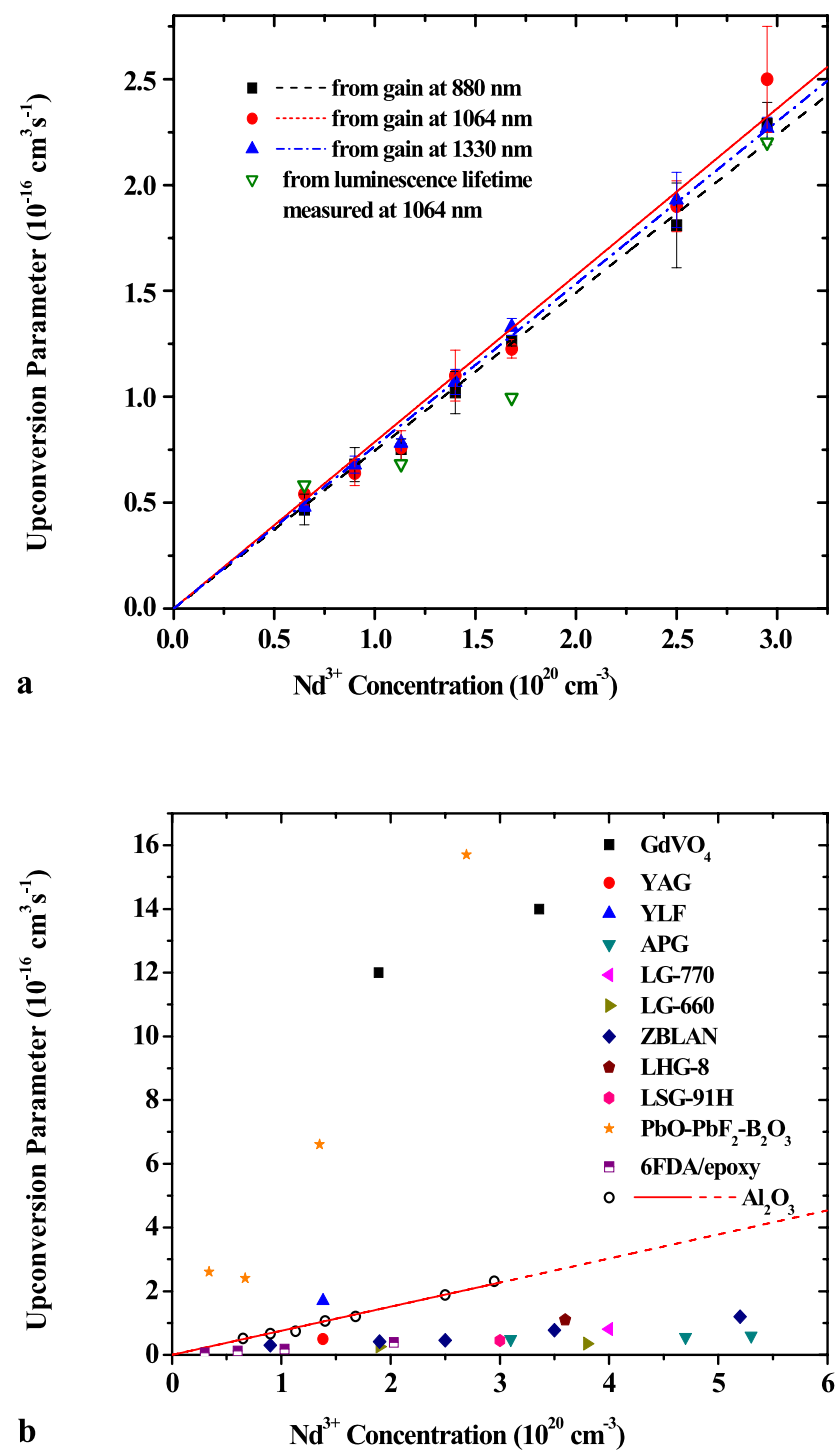

Fig. 5 ETU parameter as a function of $\mathrm{Nd}^{3+}$ concentration (a) fitted by the rate-equation model at 880,1064 , and $1330 \mathrm{~nm}$ and derived from luminescence lifetime measurement at $1064 \mathrm{~nm}$ in $\mathrm{Al}_{2} \mathrm{O}_{3}: \mathrm{Nd}^{3+}$ and (b) taken from the literature for different host materials [6, 25, 26, 30-34]

The experimentally determined spectroscopic parameters (Table 2) were used in the simulation. The population and propagation equations were solved using 128 longitudinal and 32 radial elements. The unknown ETU parameter $W_{\text {ETU }}$ was used as the only fit parameter in the simulation. The calculated gain (solid lines) is given together with the measured results in Figs. 2 and 3. The experimental and simulated results are in good agreement with each other.

\subsection{ETU parameter}

From the simulation of our $\mathrm{Al}_{2} \mathrm{O}_{3}: \mathrm{Nd}^{3+}$ channel waveguide amplifiers, the ETU parameter was determined for seven different $\mathrm{Nd}^{3+}$ concentrations independently at each of the 
Table 2 Simulation parameters of $\mathrm{Al}_{2} \mathrm{O}_{3}: \mathrm{Nd}^{3+}$ channel waveguide amplifiers

\begin{tabular}{|c|c|c|c|c|}
\hline Parameter & Value & & & \\
\hline $\mathrm{Nd}^{3+}$ concentration $\left[10^{20} \mathrm{~cm}^{-3}\right]$ & $0.65-2.95$ & & & \\
\hline${ }^{4} \mathrm{~F}_{3 / 2}$ lifetime $\tau_{4}[\mu \mathrm{s}]$ & 325 & & & \\
\hline Upconversion parameter $W_{\mathrm{ETU}}$ & free & & & \\
\hline Waveguide thickness $[\mu \mathrm{m}]$ & 2.0 & & & \\
\hline width $[\mu \mathrm{m}]$ & 0.6 & & & \\
\hline Parameter & $802 \mathrm{~nm}$ & $880 \mathrm{~nm}$ & $1064 \mathrm{~nm}$ & $1330 \mathrm{~nm}$ \\
\hline \multicolumn{5}{|l|}{ Refractive index } \\
\hline$n_{\text {core }}\left(\mathrm{Al}_{2} \mathrm{O}_{3}\right)$ & 1.660 & 1.659 & 1.658 & 1.649 \\
\hline$n_{\text {lower-cladding }}\left(\mathrm{SiO}_{2}\right)$ & 1.455 & 1.454 & 1.453 & 1.448 \\
\hline$n_{\text {cladding }}$ (air) & 1 & 1 & 1 & 1 \\
\hline Waveguide confinement factor & 0.91 & 0.89 & 0.84 & 0.75 \\
\hline \multicolumn{5}{|l|}{ Gaussian beam waist $[\mu \mathrm{m}]$} \\
\hline horizontal $w_{x}$ & 1.48 & 1.55 & 1.76 & 2.17 \\
\hline vertical $w_{y}$ & 0.35 & 0.37 & 0.42 & 0.52 \\
\hline Pump power $P_{p}[\mathrm{~mW}]$ & $0-50$ & & & \\
\hline intensity $I_{p}\left[10^{10} \mathrm{~W} / \mathrm{m}^{2}\right]$ & $0-4.08$ & & & \\
\hline Signal power $P_{s}[\mu \mathrm{W}]$ & & 1 & 1 & 1 \\
\hline intensity $I_{s}\left[10^{5} \mathrm{~W} / \mathrm{m}^{2}\right]$ & & 8.10 & 7.79 & 7.71 \\
\hline \multicolumn{5}{|l|}{ Cross section $\left[10^{-20} \mathrm{~cm}^{2}\right]$} \\
\hline pump absorption $\sigma_{\text {abs }}^{p}$ & 0.79 & & & \\
\hline signal reabsorption $\sigma_{\text {abs }}^{s}$ & & 0.35 & & \\
\hline signal emission $\sigma_{\mathrm{em}}^{s}$ & & 0.82 & 2.01 & 0.70 \\
\hline
\end{tabular}

three signal wavelengths (Fig. 5a). For each concentration, the values fitted to the gain measured at the three different wavelengths show less than $10 \%$ deviation from each other; only for the $\mathrm{Nd}^{3+}$ concentration of $0.65 \times 10^{20} \mathrm{~cm}^{-3}$, a deviation of $14 \%$ was observed. The deviation is caused by experimental errors in the spectroscopic measurements and gain investigations. The ETU parameter obtained in this way in our waveguides exhibits a linear dependence on $\mathrm{Nd}^{3+}$ concentration, see Fig. 5a.

In addition, the ETU parameter was also studied by the measured luminescence decay curves (Fig. 1c). By setting the pump and signal terms to zero and solving (7) or (12) time-dependently, the Bernoulli equation is derived:

$N_{4}(t)=\frac{N_{4}(t=0) \exp \left(-t / \tau_{4}\right)}{1+W_{\mathrm{ETU}} N_{4}(t=0) \tau_{4}\left[1-\exp \left(-t / \tau_{4}\right)\right]}$.

The intrinsic lifetime $\tau_{4}$ equals the luminescence lifetime obtained from the exponential decay at very low dopant concentration; it remains constant at all dopant concentrations. The ETU parameter was determined by fitting (16) to the measured luminescence decay curves. The fitted curves show very good agreement with the measured decay curves at $1064 \mathrm{~nm}$ (see Fig. 1c), which is an indication that this simplified model, assuming a sea of excitations smeared out over the excitation volume by infinitely fast energy migration within the ${ }^{4} \mathrm{~F}_{3 / 2}$ level, is valid for ETU in the $\mathrm{Al}_{2} \mathrm{O}_{3}: \mathrm{Nd}^{3+}$ system. With this method, values of the ETU parameter of $0.58,0.68,1.00$, and $2.20 \times 10^{-16} \mathrm{~cm}^{3} \mathrm{~s}^{-1}$ were determined at $\mathrm{Nd}^{3+}$ concentrations of $0.65,1.13,1.68$, and $2.95 \times 10^{20} \mathrm{~cm}^{-3}$, respectively (open dots in Fig. 5a). The main error in this approach is the deviation of the point were $t=0$ in the decay curve, due to the power fluctuation of the excitation laser.

The deviation of the ETU parameters determined from the two independent approaches is between $6.5-23 \%$ for different $\mathrm{Nd}^{3+}$ concentration, which is reasonable considering the errors inherent to both approaches. The agreement obtained between the two independent approaches indicates that the obtained values are reliable.

Assuming that the ETU parameter of $\mathrm{Nd}^{3+}$ in $\mathrm{Al}_{2} \mathrm{O}_{3}$ increases linearly with ion concentration, we averaged the values obtained for each concentration. Figure $5 \mathrm{~b}$ shows the averaged ETU parameter for seven $\mathrm{Nd}^{3+}$ concentrations (open circles) and a linear fit. The ETU parameters at different $\mathrm{Nd}^{3+}$ concentrations in various materials $[6,25,26,30-34]$ are also displayed in the same figure for comparison. $\mathrm{Al}_{2} \mathrm{O}_{3}: \mathrm{Nd}^{3+}$ exhibits a higher ETU parameter 
than the majority of glass, polymer, and crystalline materials.

\section{Conclusion}

$\mathrm{Al}_{2} \mathrm{O}_{3}: \mathrm{Nd}^{3+}$ layers have been deposited on thermally oxidized $\mathrm{Si}$ substrates, and single-mode channel waveguides have been fabricated. At the investigated signal wavelengths of $880 \mathrm{~nm}, 1064 \mathrm{~nm}$, and $1330 \mathrm{~nm}$, small-signal gain of $1.57 \mathrm{~dB} / \mathrm{cm}, 6.30 \mathrm{~dB} / \mathrm{cm}$, and $1.93 \mathrm{~dB} / \mathrm{cm}$, respectively, has been demonstrated for individually optimized $\mathrm{Nd}^{3+}$ concentrations. A maximum gain of $3.0 \mathrm{~dB}, 14.4 \mathrm{~dB}$, and $5.1 \mathrm{~dB}$, respectively, has been obtained. On the ground-state transition, net optical gain has been demonstrated across the wavelength range $865-930 \mathrm{~nm}$, with good agreement between calculated and measured gain spectra. With the gain simulated by a rate-equation model and by fitting of measured luminescence decay curves, the ETU parameter of $\mathrm{Nd}^{3+}$ in $\mathrm{Al}_{2} \mathrm{O}_{3}$ has been studied.

Such waveguide devices may be well suited for providing optical gain in integrated optical applications, e.g., lossless data transmission in optical interconnects and telecommunication, signal enhancement in integrated Raman spectroscopy or lasers integrated into opto-fluidic chips.

Acknowledgements This work was supported by the Dutch Technology Foundation STW and carried out within the framework of project TOE 6986 "Optical Backplanes.”

Open Access This article is distributed under the terms of the Creative Commons Attribution Noncommercial License which permits any noncommercial use, distribution, and reproduction in any medium, provided the original author(s) and source are credited.

\section{References}

1. E. Lallier, J.P. Pocholle, M. Papuchon, M. De Micheli, M.J. Li, Q. He, D.B. Ostrowsky, C. Grezes-Besset, E. Pelletier, Opt. Lett. 15, 682 (1990)

2. L.H. Slooff, A. van Blaaderen, A. Polman, G.A. Hebbink, S.I. Klink, F.C.J.M. Van Veggel, D.N. Reinhoudt, J.W. Hofstraat, J. Appl. Phys. 91, 3955 (2002)

3. F. Gardillou, L. Bastard, J.E. Broquin, Appl. Phys. Lett. 85, 5176 (2004)

4. A. Kahn, H. Kühn, S. Heinrich, K. Petermann, J.D.B. Bradley, K. Wörhoff, M. Pollnau, Y. Kuzminykh, G. Huber, J. Opt. Soc. Am. B 25, 2008 (1850)

5. J. Yang, M.B.J. Diemeer, D. Geskus, G. Sengo, M. Pollnau, A. Driessen, Opt. Lett. 34, 473 (2009)
6. J. Yang, M.B.J. Diemeer, G. Sengo, M. Pollnau, A. Driessen, IEEE J. Quantum Electron. 46, 1043 (2010)

7. K. Wörhoff, J.D.B. Bradley, F. Ay, D. Geskus, T.P. Blauwendraat, M. Pollnau, IEEE J. Quantum Electron. 45, 454 (2009)

8. J.D.B. Bradley, M. Costa e Silva, M. Gay, L. Bramerie, A. Driessen, K. Wörhoff, J.C. Simon, M. Pollnau, Opt. Express 17, 22201 (2009)

9. J.D.B. Bradley, L. Agazzi, D. Geskus, F. Ay, K. Wörhoff, M. Pollnau, J. Opt. Soc. Am. B 27, 187 (2010)

10. D.S. Gill, A.A. Anderson, R.W. Eason, T.J. Warburton, D.P. Shepherd, Appl. Phys. Lett. 69, 10 (1996)

11. J.R. Lee, H.J. Baker, G.J. Friel, G.J. Hilton, D.R. Hall, Opt. Lett. 27, 524 (2002)

12. J. Yang, M.B.J. Diemeer, C. Grivas, G. Sengo, A. Driessen, M. Pollnau, Laser Phys. Lett. (2010). doi:10.1002/ lapl.201010048

13. S. Uhlig, M. Robertsson, J. Lightw. Technol. 24, 1710 (2006)

14. J. Moisel, J. Guttmann, H.P. Huber, O. Krumpholz, M. Rode, Opt. Eng. 39, 673 (2000)

15. S. Lehmacher, A. Neyer, Electron. Lett. 36, 1052 (2000)

16. L. Dellmann, C. Berger, R. Beyeler, R. Dangel, M. Gmür, R. Hamelin, F. Horst, T. Lamprecht, N. Meier, T. Morf, S. Oggioni, M. Spreafico, R. Stevens, B.J. Offrein, $120 \mathrm{~Gb} / \mathrm{s}$ optical card-to-card interconnect link demonstrator with embedded waveguides. in 57th Electronic Components and Technology Conference Proceeding (Reno, 2007), pp. 1288-1293

17. P.J. Caspers, G.W. Lucassen, E.A. Carter, H.A. Bruining, G.J. Puppels, J. Invest. Dermatol. 116, 434 (2001)

18. P.J. Caspers, G.W. Lucassen, G.J. Puppels, Biophys. J. 85, 572 (2003)

19. J.D.B. Bradley, F. Ay, K. Wörhoff, M. Pollnau, Appl. Phys. B 89, 311 (2007)

20. Y. Okamura, S. Yoshinaka, S. Yamamoto, Appl. Opt. 22, 3892 (1983)

21. A. Kahn, Y. Kuzminykh, H. Scheife, G. Huber, J. Opt. Soc. Am. B 24, 1571 (2007)

22. B.R. Judd, Phys. Rev. 127, 750 (1962)

23. G.S. Ofelt, J. Chem. Phys. 37, 511 (1962)

24. A.A. Kaminskij, Laser Crystals (Springer, Berlin, 1979)

25. M. Pollnau, P.J. Hardman, W.A. Clarkson, D.C. Hanna, Opt. Commun. 147, 203 (1998)

26. M. Pollnau, P.J. Hardman, M.A. Kern, W.A. Clarkson, D.C. Hanna, Phys. Rev. B 58, 16076 (1998)

27. W.B. Fowler, D.L. Dexter, Phys. Rev. 128, 2154 (1962)

28. D.E. McCumber, Phys. Rev. A 136, 954 (1964)

29. PhoenixX. http://www.phoenixbv.com

30. V. Ostroumov, T. Jensen, J.P. Meyn, G. Huber, J. Opt. Soc. Am. B 15, 1052 (1998)

31. S.A. Payne, G.D. Wilke, L.K. Smith, W.F. Krupke, Opt. Commun. 111, 263 (1994)

32. J.L. Doualan, C. Maunier, D. Descamps, J. Landais, R. Moncorgé, Phys. Rev. B 62, 4459 (2000)

33. L.C. Courrol, B.L.S. de Lima, L.R.P. Kassab, V.D. Del Cacho, S.H. Tatumi, L. Gomes, N.U. Wetter, J. Non-Cryst. Solids 348, 98 (2004)

34. S.L. Oliveira, D.F. de Sousa, A.A. Andrade, L.A.O. Nunes, T. Catunda, J. Appl. Phys. 103, 023103 (2008) 